\title{
Visualization of G-quadruplexes in gel and in live cells by a near-infrared fluorescent probe
}

Fan Wu ${ }^{\mathrm{a}}$, Chaoxing Liu ${ }^{\mathrm{a}}$, Yuqi Chen ${ }^{\mathrm{a}}$, Shixi Yang ${ }^{\mathrm{a}}$, Jiahui $\mathrm{Xu}^{\mathrm{a}}$, Rong Huang ${ }^{\mathrm{c}}$, Xiang Wang ${ }^{\mathrm{a}}$, Manjia Li ${ }^{\mathrm{a}}$, Wenting Liu ${ }^{\mathrm{a}}$, Wuxiang Mao*b and Xiang Zhou*a

a College of Chemistry and Molecular Sciences, Key Laboratory of Biomedical Polymers of Ministry of Education, Wuhan University Wuhan, Hubei, 430072, (P. R. of China)

${ }^{b}$ Hubei Collaborative Innovation Center for Green Transformation of Bio-resources, College of Life Sciences, Hubei University, Wuhan, Hubei 430062,P.R.China.

${ }^{c}$ College of Pharmacy, South Central University for Nationalities, Wuhan, Hubei, 430073, P. R.

China

*Corresponding author:

Tel: (+) 86-27-68756663

Fax: (+) 86-27-87336380

Email: xzhou@whu.edu.cn, maowuxiang@163.com

\$ Both authors contributed equally this work. 


\section{ABSTRACT}

G-quadruplexes, one of the most significant secondary structure of nucleic acid, are formed by stacking $G$ quartets, which received broad interests due to their involvement in telomere function, gene transcription and recombination. As for ligand, better selectivity for G-quadruplex against other DNA or RNA structures and higher ability to stabilize G-quadruplex are necessary. In addition, developing a new probe to recognize G-quadruplex is desired for utilizing G-quadruplex structure to relevant biological processes. In this study, we report a Cy5 labelled ligand (named PDP-Cy5) developed as a near-infrared fluorescent ligand for G-quadruplexes both in DNA and RNA. The results indicated that PDP-Cy5 selectively induced the formation of intramolecular G-quadruplexes with strong binding affinity. Furthermore, this Cy5 labelled ligand can effectively stabilize G-quadruplexes. Moreover, the direct visualization of G-quadruplexes in gel, even on cell level is realized by using PDP-Cy5.

Keywords:

Fluorescent probe

G-quadruplex

Direct visualization

Cell imaging 


\section{Introduction}

G-rich sequences built around tetrads of hydrogen-bonded guanine bases can form G-quadruplexes which are higher-order DNA and RNA structures [1]. In DNA sequences, the G-quadruplexes have been found to exist in telomere structures at the ends of chromosomes[2] and in promoter regions of some oncogenes [3]. While G-quadruplexes in RNA have been identified in telomeric transcripts [4], as well as in 5'- or 3'-UTRs of mRNAs [5-7]. In addition, G-quadruplex structures have also been found to exist in tRNA-derived, stress-induced RNAs (tiRNAs) and may play important roles in ensuring motor neuron viability [8]. Depending on the monovalent cations they possess or their precise sequences, G-quadruplexes have different topological forms with characteristic biological activities. For instance, in presence of $\mathrm{K}^{+}$and/or $\mathrm{Na}^{+}$, single stranded telomeric sequences can form into three different conformations including parallel, antiparallel and mixed types [9]. According to the results reported by Balasubramanian's group, BG4, a G-quadruplex specific antibody, has been reported to exhibit the evidence of existence of DNA/RNA G-quadruplex in vivo $[10,11]$. These studies indicated that the existence of G-quadruplex in genes reveals G-quadruplex might be involved in gene expression [12, 13] telomere maintenance [14], replication stalling [15], DNA recombination [16] and splicing processes [17]. Moreover, G-quadruplexes had been used in bioengineering applications in form of aptamers. For example, thrombin-binding DNA aptamer, forming an intramolecular G-quadruplex structure in solution, has been utilized to inhibit thrombin catalyzed fibrin clot formation owing to its strong affinity to 
thrombin protein [18]. Above all, these previous findings suggested that G-quadruplex formation and structures are the important research filed in chemical biology.

G-quadruplexes have been studied to show great significance for cell proliferation, drug development, and cancer research, thus a number of ligands [19-22], fluorescent probes [23-26] and antibodies [10, 11] have been synthesized and studied, such as TMPyP4 [21], ThT [23] and BG4 [10, 11], respectively. Nagasawa and his coworkers have developed a BODIPY-labelled macrocyclic heptaoxazole constituted with G-quadruplex ligand and BODIPY fluorophore to avoid the lack of inherent fluorescence of the previous G-quadruplex ligand itself [27]. As for ligand, better selectivity for G-quadruplex against other DNA or RNA structures and higher ability to stabilize G-quadruplex are necessary. In addition, developing a new probe to recognize G-quadruplex is desired for utilizing G-quadruplex structure to relevant biological processes.

An ideal G-quadruplex ligand should have several structural features, (1) an electron-rich aromatic surface, (2) the potential to adopt a functional planar conformation and (3) decent water solubility. Pyridostatin [22], named as PDS, is a representative G-quadruplex ligand and it has all these features. Therefore choosing pyridostatin derivative as G-quadruplex ligand is a desirable way to recognize G-quadruplex over other nucleic acid structures. Compared to the UV and visible lights, the light in the near-infrared region $(650-900 \mathrm{~nm})$ has weaker absorption and auto-fluorescence background, less light scattering, and minimized photo damage to organisms [28]. Fortunately, Cy5 is an NIR fluorophore and has characteristics above. 
In this work, we have developed a probe (PDP-Cy5), which conjugates G-quadruplex ligand pyridostatin derivative (PDP) with fluorophore Cy5 (Scheme 1), successfully avoiding the lack of inherent fluorescent of PDS. Interestingly, this probe presents strong binding affinity, higher selectivity and effectively stabilizes G-quadruplexes both in DNA and RNA. Moreover, PDP-Cy5 can directly visualize G-quadruplexes in gel, even on cell level.

\section{[insert Sheme 1]}

\section{Material and methods}

\subsection{Materials and equipments}

Solvent, compounds and reagents were bought from Sigma-Aldrich. All the DNA oligonucleotides were synthesized and purified with PAGE by Sangon Biochemistry Co.,Ltd. (Shanghai, China), and all the RNA oligonucleotides were synthesized and purified with HPLC by Takara Bio. (Dalian, China). UV absorbance spectrum was collected on UV-2550 spectrophotometer (Shimadzu, Japan). Fluorescent emission spectra were collected on PerkinElmer LS 55 (PerkinElmer, USA). CD data were obtained by Jasco-810 spectro-polarimeter (Jasco, Easton, MD, USA). Native gel electrophoresis data were collected on Molecular Imager Pharos FX TM (Bio-Rad, USA). Confocal laser scanning microscopy analysis was measured with Nikon TE2000-E. ${ }^{1} \mathrm{H}$ and ${ }^{13} \mathrm{C}$ NMR spectra were recorded on Varian Mercury 300 
spectrometers, respectively. HRMS was recorded on Thermo Fisher LTO Orbitrap XL. HPLC purification was carried out by using a Venusil XBP C18, 10 $\mu$ m column $(10 \times$ $250 \mathrm{~mm}$ ) (Agela Technologies, China) and a gradient elution with $\mathrm{H}_{2} \mathrm{O} / \mathrm{MeCN}$ at a flow rate of $3.0 \mathrm{~mL} / \mathrm{min}$.

\subsection{Synthesis}

\section{[insert Sheme 2]}

Synthesis route for PDP-Cy5 was present in Scheme 2. The compound PDP [22b] and Cy5-NHS ester [29, 30] was synthesized using a previously reported procedure. To a solution of PDP $(20.0 \mathrm{mg}, 28.3 \mu \mathrm{mol})$ in dry DMF $(1 \mathrm{~mL})$, Cy5-NHS ester $\left(25.0 \mathrm{mg}, 40.6 \mu \mathrm{mol}\right.$, Lumiprobe) and $\mathrm{NaHCO}_{3}(23.0 \mathrm{mg}, 270$ $\mu \mathrm{mol})$ were added, and stirred for 36 hours at $60{ }^{\circ} \mathrm{C}$ under Argon gas atmosphere and concentrated in vacuo. The residue was purified by HPLC (gradient: 10\% $\mathrm{MeCN} / 90 \% \mathrm{H}_{2} \mathrm{O}, 100 \% \mathrm{MeCN}$ over $40 \mathrm{~min}, \mathrm{Rt}=25.0-26.0 \mathrm{~min}$ ) to give PDP-Cy5 (10.2 mg, 8.5 $\mu \mathrm{mol}$, yield 30\%). ${ }^{1} \mathrm{H}$ NMR (300 MHz, CD $\left.3 \mathrm{OD}\right) \delta 8.38(\mathrm{~d}, \mathrm{~J}=8.1 \mathrm{~Hz}$, 2H), $8.21(\mathrm{t}, \mathrm{J}=12.8 \mathrm{~Hz}, 2 \mathrm{H}), 8.11(\mathrm{~s}, 2 \mathrm{H}), 8.06(\mathrm{~s}, 2 \mathrm{H}), 8.02-7.99(\mathrm{~m}, 2 \mathrm{H}), 7.88(\mathrm{t}$, $\mathrm{J}=7.5 \mathrm{~Hz}, 2 \mathrm{H}) .7 .64(\mathrm{t}, \mathrm{J}=7.6 \mathrm{~Hz}, 2 \mathrm{H}), 7.44(\mathrm{~d}, \mathrm{~J}=7.2 \mathrm{~Hz}, 2 \mathrm{H}), 7.41-7.30(\mathrm{~m}$, 2H), $7.23(\mathrm{dd}, \mathrm{J}=17.7,8.3 \mathrm{~Hz}, 4 \mathrm{H}), 6.55(\mathrm{t}, \mathrm{J}=12.4 \mathrm{~Hz}, 1 \mathrm{H}), 6.24(\mathrm{~d}, \mathrm{~J}=7.2 \mathrm{~Hz}$, 1H), $6.19(\mathrm{~d}, \mathrm{~J}=7.0 \mathrm{~Hz}, 1 \mathrm{H}) .4 .84(\mathrm{~m}, 4 \mathrm{H}), 4.39(\mathrm{~m}, 2 \mathrm{H}), 4.06(\mathrm{~d}, \mathrm{~J}=7.5 \mathrm{~Hz}, 2 \mathrm{H})$, $3.98(\mathrm{~m}, 4 \mathrm{H}), 3.89(\mathrm{~m}, 4 \mathrm{H}), 3.70(\mathrm{~m}, 2 \mathrm{H}), 3.57(\mathrm{~s}, 3 \mathrm{H}), 3.35(\mathrm{~m}, 2 \mathrm{H}), 3.25-3.17(\mathrm{~m}$, 
2H), 2.30-2.08 (m, 10H), 1.79-0.9 (m, 21H) ppm; ${ }^{13} \mathrm{C}$ NMR $\left(75 \mathrm{MHz}, \mathrm{CD}_{3} \mathrm{OD}\right) \mathrm{d}$ $174.97,173.81,173.05,168.31,167.00,163.48,153.99,150.31,148.96,142.74$, $142.10,141.22,141.08,138.06,134.09,128.34,128.27,127.33,125.25,124.83$, $123.18,122.00,121.84,120.37,118.20,113.53,110.56,110.39,102.87,94.19$, $67.87,66.10,54.50,52.92,49.08,43.41,38.09,35.28,30.15,26.79,26.60,26.44$, 26.01, 25.11, 22.62, 22.57 ppm; HRMS (ESI), calcd for $\mathrm{C}_{71} \mathrm{H}_{81} \mathrm{~N}_{10} \mathrm{O}_{6}{ }^{+}$[M-Cl-] 1169.63351, found 1169.62927.

\subsection{Circular dichroism (CD) experiments}

CD spectra were measured at room temperature using a quartz cell with a $1 \mathrm{~cm}$ path length; CD spectra were collected from $220 \mathrm{~nm}$ to $320 \mathrm{~nm}$ and with a scanning speed of $200 \mathrm{~nm} / \mathrm{min}$. The bandwidth was $5 \mathrm{~nm}$, and the response time was $2 \mathrm{~s}$. All the samples were in $10 \mathrm{mM}$ Tris- $\mathrm{HCl}$ buffer ( $\mathrm{pH} 7.4)$, and the concentration of DNA or RNA G-quadruplexes was $8 \mu \mathrm{M}$ with 5.0 equiv. PDP-Cy5 or/and $100 \mathrm{mM} \mathrm{K}$. Melting curves were measured at $265 \mathrm{~nm}$ and the range of temperature was $4{ }^{\circ} \mathrm{C}$ $-100{ }^{\circ} \mathrm{C}$.

\subsection{Thiazole orange (TO) displacement assay}

Thiazole orange displacement assay was conducted according to the previous literature [31]. G-quadruplexes and double strand DNA were prefolded (as shown in Supplementary Table S1, $0.25 \mu \mathrm{M}$ ) in a $10 \mathrm{mM}$ Tris-HCl, $\mathrm{pH}$ 7.4, $100 \mathrm{mM} \mathrm{KCl}$ buffer, 
then thiazole orange $(0.50 \mu \mathrm{M})$ was added and mixed at room temperature, and the fluorescence spectrum were recorded (excitation: $501 \mathrm{~nm}$, fluorescence area: 500-650 $\mathrm{nm})$ as a primary fluorescent intensity $\left(\mathrm{FI}_{0}\right)$. Then, increasing concentration of PDP-Cy5 (from 0.125 to $7.5 \mu \mathrm{M}$ ) were added by a 3 min equilibration period before the fluorescence spectrum was recorded (FI). The $\mathrm{DC}_{50}$ of PDP-Cy5, the concentration required for replace 50\% TO, was calculated from formula (Percentage $\left.=100-\left[\left(\mathrm{FI} / \mathrm{FI}_{0}\right) \times 100\right]\right)$ at $535 \mathrm{~nm}$, and the percentage for $\mathrm{DC}_{50}$ was 50 .

\subsection{Native Gel Electrophoresis.}

$1 \mu \mathrm{M}$ FAM-labeled DNA or RNA G-rich sequences was added into the solution containing $10 \mathrm{mM}$ Tris- $\mathrm{HCl}(\mathrm{pH}=7.4), 100 \mathrm{mM} \mathrm{KCl}$ depending on conditions. PDP-Cy5 were then added into the mixture to achieve indicated concentrations. The total volume of each sample was $10 \mu \mathrm{L}$. Each sample was treated with heat denaturation and renaturation before loaded onto gel. Native gel electrophoresis was run on $20 \%$ polyacrylamide gel, at $4{ }^{\circ} \mathrm{C}, 5 \mathrm{~V} / \mathrm{cm}$ in $1 \times \mathrm{TBE}$ buffer. And native gel electrophoresis data were collected on Molecular Imager Pharos FX TM (Bio-Rad, USA). The images were obtained by 490-530 $\mathrm{nm}$ band-pass filter (FAM) and 640-700 $\mathrm{nm}$ band-pass filter (Cy5) respectively then merged in one image.

\subsection{Cell culture and confocal imaging of colocalization}


HeLa human cervical carcinoma cells (CCTCC, China) were cultured in DMEM (Hyclone, China) supplemented with 12\% FBS (Hangzhou Sijiqing Biological engineering Materials Corporation, China). Cells were maintained in a humidified atmosphere of $5 / 95(\mathrm{~V} / \mathrm{V}) \mathrm{CO}_{2} /$ air at $37^{\circ} \mathrm{C}$.

HeLa cells seeded on 35-mm glass-bottomed dishes (Nest) were washed with 2 mL PBS (10mM) buffer, and then change medium by DMEM supplemented with 12\% FBS. 100 pmol prefolded FAM-labelled c-kit or BCL2 sequence was transfected to cells using lipofectamine 3000 (Invitrogen, USA) and incubated 4h in a humidified atmosphere of 5/95 (V/V) $\mathrm{CO}_{2} /$ air at $37{ }^{\circ} \mathrm{C}$. Then $1 \mu \mathrm{M}$ PDP-Cy5 was added and incubated in another $2 \mathrm{~h}$. After washed with $2 \mathrm{~mL}$ PBS (10 mM) buffer three times (each time for $10 \mathrm{~min}$ ), the cells were treated with DAPI (500 ng/mL) 20 min at $37^{\circ} \mathrm{C}$. The cells were mounted on the microscope stage after washing with PBS (10 $\mathrm{mM})$ buffer again. White-light laser was used as the light source. The excitation wavelength was $405 \mathrm{~nm}$ (DAPI), $488 \mathrm{~nm}$ (FAM) and 640 $\mathrm{nm}$ (PDP-Cy5), and the emission wavelength was $415 \mathrm{~nm}$ (DAPI), $520 \mathrm{~nm}$ (FAM) and $660 \mathrm{~nm}$ (PDP-Cy5), respectively.

\subsection{Cell viability assay}

HeLa cells were digested using trypsin and washed with $10 \mathrm{mM}$ PBS buffer. The cells were added into a 96-well plate and incubated at $37{ }^{\circ} \mathrm{C}$ in a $5 \%$ $\mathrm{CO}_{2}$-containing incubator overnight for attachment. Then the cells were treated 
with PDP-Cy5 (100 nM-200 $\mu \mathrm{M}$ ) for $24 \mathrm{~h}$. Control cells (without PDP-Cy5) were treated under the same conditions. Cell survival was evaluated using an MTT assay. $20 \mu \mathrm{L}$ of a freshly prepared MTT solution $\left(5 \mathrm{mg} \bullet \mathrm{mL}^{-1}\right.$ in PBS) was added to each well. After $4 \mathrm{~h}$ incubation, the medium was removed and $150 \mu \mathrm{L}$ DMSO was added to each well. The optical density values were detected at $492 \mathrm{~nm}$ and the cytotoxicity data were expressed as $\mathrm{IC}_{50}$ values.

\section{Results and discussion}

\subsection{Preparation and photophysical properties of PDP-Cy5.}

PDP-Cy5 was synthesized by reacting PDP with the N-hydroxysuccinimide (NHS) ester of Cy5 in the presence of sodium bicarbonate (Scheme 2). The structure characterization was shown in supporting information (Fig. S1-S3). The new probe, PDP-Cy5 had a max absorbance at $642 \mathrm{~nm}$ (Fig. S4) and exhibited red fluorescence emission at $666 \mathrm{~nm}$ under $642 \mathrm{~nm}$ irradiation (Fig. S5), just like Cy5 fluorophore. All the data shows that we have successfully synthesized a near-infrared fluorescent ligand for G-quadruplexes.

\subsubsection{Stabilization of G-quadruplexes through PDP-Cy5}

As a G-quadruplex probe, it is important to have strong ability to stabilize G-quadruplexes and great selectivity. Firstly, we tested PDP-Cy5 by means of circular 
dichroism (CD) analysis to evaluate its ability to stabilize G-quadruplexes. Four different DNA G-quadruplex forming oligonucleotides (c-kit, bcl27, c-myc, telo24) [27] and three types of RNA G-quadruplexes (BCL2, NRAS, TERRA) [11] were tested here as representatives. In Fig. 1A, as for c-kit sequence, a random structure was formed in absence of monovalent cations or G-quadruplex ligand (PDP-Cy5). But when the sequence was treated with 5.0 equiv. PDP-Cy5, a typical positive peak at $265 \mathrm{~nm}$ and negative peak at $240 \mathrm{~nm}$ were observed in CD spectrum, which means that random structure has changed into parallel G-quadruplex, just like treated with $100 \mathrm{mM} \mathrm{K}^{+}$(Red line in Fig. 1A). Furthermore, other three DNA G-quadruplex forming oligonucleotides (bcl27, c-myc and telo24) can also be induced and stabilized to DNA G-quadruplexes by 5.0 equiv. PDP-Cy5 (Fig.S6).

Secondly, we used a short oligonucleotide BCL2, a RNA G-quadruplex sequence in 5'-UTR to study the influence of this probe to RNA G-quadruplex (Fig. 1B). Just as Fig. 1B, after the BCL2 sequence was treated with 5.0 equiv. PDP-Cy5, a characteristic positive peak at $265 \mathrm{~nm}$ and a negative peak at $240 \mathrm{~nm}$ appeared in CD spectrum, suggesting RNA G-quadruplex has been stabilized. To our surprise, when the sample was treated with 5.0 equiv. PDP-Cy5 and $100 \mathrm{mM} \mathrm{K}^{+}$at the same time, the typical positive peak at $265 \mathrm{~nm}$ did not give the enhancement, but it was in the middle of signals when treated with $100 \mathrm{mM} \mathrm{K}^{+}$or PDP-Cy5, respectively. We proposed that in this structure PDP-Cy5 and $\mathrm{K}^{+}$were in the equilibrium of binding with G-quadruplex, so the actual concentration of $\mathrm{K}^{+}$was less than $100 \mathrm{mM}$. CD spectra of other RNA G-quadruplex sequence, such as NRAS and TERRA also showed that 
PDP-Cy5 had the ability to stabilize RNA G-quadruplexes (Fig. S7).

Thirdly, in order to evaluate the ability of ligand to stabilize G-quadruplexes more deep, the differences of the melting temperatures $\left(\Delta \mathrm{T}_{\mathrm{m}}\right)$ of $\mathrm{G}$-quadruplex under various condition were investigated by $\mathrm{CD}$ melting experiment. In the presence of 5.0 equiv. PDP-Cy5, the melting temperature of DNA G-quadruplexes drastically increased with $5 \mathrm{mM} \mathrm{K}^{+}$(Fig. 1C, S8). For RNA G-quadruplexes were pretty stable with $5 \mathrm{mM} \mathrm{K}^{+}$, we decreased the concentration of $\mathrm{K}^{+}$to $500 \mu \mathrm{M}$ to investigate the difference of the melting temperatures caused by PDP-Cy5. It turned out that RNA G-quadruplexes could not be completely unfolded even at $90^{\circ} \mathrm{C}$ (Fig. 1D, S9). These results demonstrated extremely high thermodynamic stability for G-quadruplexes after the sequences were incubated with 5.0 equiv. PDP-Cy5. All the $\Delta \mathrm{T}_{\mathrm{m}}$ data presented in Table 1.

[insert Fig. 1 and Tabel 1]

\subsection{Binding ability of PDP-Cy5 with G-quadruplexes.}

Further, we evaluated the selectivity of PDP-Cy5 for G-quadruplexes after demonstrating PDP-Cy5 effectively stabilize RNA and DNA G-quadruplex. Thiazole orange (TO) could bind to dsDNA and G-quadruplex with an increase of fluorescence at $530 \mathrm{~nm}$ [32], and TO displacement was based on the loss of fluorescence of duplexes or quadruplexes with thiazole orange when adding other ligand [31]. Thus TO displacement is a facile and effective method to find out the binding affinity of 
PDP-Cy5 with G-quadruplexes or other duplexes. In this assay, DNA G-quadruplexes (c-kit, bcl27, c-myc and telo24) and RNA G- quadruplexes (BCL2, NRAS and TERRA) were studied. As DNA duplex and hybrid RNA/DNA duplex are common form in vivo, we also added this two type of duplexes into TO displacement assay. The results in Fig. 2 and Table 2 indicated that PDP-Cy5 can effectively displace TO from all the different G-quadruplexes both in DNA and RNA, whereas no significant interaction was observed with dsDNA or hybrid DNA/RNA duplex, suggesting PDP-Cy5 selectively binds with G-quadruplexes.

[insert Fig. 2 and Table 2]

\subsection{Direct visualization of G-quadruplexes in gel.}

In addition, we can also use native gel electrophoresis to examine the selectivity of PDP-Cy5 for G-quadruplexes. Thus, visualization of DNA and RNA G-complex was successfully achieved by using this strategy (Fig. 3). For native gel electrophoresis, 5' FAM labelled DNA G-quadruplexes (c-kit, bcl27, c-myc and telo24) and RNA G-quadruplexes (BCL2, NRAS and TERRA) and other non-quadruplex forming oligonucleotides (ssDNA, dsDNA, RNA hairpin and miR 21) were prepared. In the presence of PDP-Cy5, red bands $\left(\lambda_{\mathrm{ex}}=648 \mathrm{~nm}, 640-700 \mathrm{~nm}\right.$ band-pass filter) associated with c-kit could be observed, and with the increase of PDP-Cy5, the intensity of red bands were enhanced correspondingly. On the other hand, the intensity of green bands, standing for FAM labelled c-kit itself $\left(\lambda_{\mathrm{ex}}=488 \mathrm{~nm}, 490-530\right.$ 
$\mathrm{nm}$ band-pass filter) were reduced (Fig. 3A, lane 1-6) because of föster resonance energy transfer (FRET) of FAM and Cy5 fluorophore [33]. Although at first glance, the FRET efficiency may not intuitive since the overlap between the donor fluorescence emission (FAM) and acceptor absorption appears to be so low, the major factor affect FRET between two dyes is the distance [34]. After incubation with PDP-Cy5, G-quadruplexes formed and reacted with PDP-Cy5, then the distance between FAM at 5' end of oligonucleotides and Cy5 fluorophore decreased, inducing FRET phenomenon. The results showed that the amount of the c-kit G-quadruplex in red band increased in a way which was directly proportional to the concentration of PDP-Cy5, suggesting PDP-Cy5 had induced and stabilized G- quadruplex c-kit without $\mathrm{K}^{+}$. Moreover, when the amount of PDP-Cy5 was 5 times of DNA G-quadruplexes, nearly all the G-quadruplexes interacted with PDP-Cy5. In lane 7, $100 \mathrm{mM} \mathrm{K} \mathrm{K}^{+}$was added into reaction solution containing $5 \mu \mathrm{M}$ PDP-Cy5, both red band and green band changed similarly to lane 6 . The same phenomena were observed in Fig. 3B and Fig. S10. Then we use different types of DNA or RNA in the presence or absence of $5 \mu \mathrm{M}$ PDP-Cy5 containing $100 \mathrm{mM} \mathrm{K}^{+}$in $10 \mathrm{mM}$ Tris- $\mathrm{HCl}$, pH 7.4 (Fig. 3C-3F). After G- quadruplex sequences were incubated with PDP-Cy5, the red bands appeared while green bands disappeared (Lane 2 in Fig. 3C and 3E). It turned out PDP-Cy5 could completely interact with both DNA and RNA G-quadruplexes. But other structures such as single strand DNA or RNA, double strand DNA and RNA hairpin did not interact with $5 \mu \mathrm{M}$ PDP-Cy5, where no red bands were observed and green bands had no changes in lane 2 (Fig. 3D, 3F). To 
make it more convincible, we also tried that $5 \mu \mathrm{M}$ PDP-Cy5 and $100 \mathrm{mM} \mathrm{K}{ }^{+}$were added into reaction solution without FAM labelled DNA or RNA sequences, and no red band appeared, just as estimated (Lane 3 in Fig. 3C-3F), indicating PDP-Cy5 itself had no ability to shift in native gel electrophoresis. All these results indicated PDP-Cy5 had exhibited good selectivity for G-quadruplexes and was easy to realize the visualization of G-quadruplexes both in DNA and RNA in vitro gel native gel electrophoresis.

[insert Fig. 3]

\subsection{Application of PDP-Cy5 for intracellular G-quadruplex imaging}

After demonstrating that PDP-Cy5 could realize direct visualization of G-quadruplexes in gel, we investigated the interaction between PDP-Cy5 and G-quadruplexes on cell level by confocal laser scanning microscopy (Fig. 4). In order to measure if PDP-Cy5 could achieve the visualization of G-quadruplexes on cell level, colocalization experiment of the prefolded of FAM labelled G-quadruplexes and PDP-Cy5 is proper and intuitive. Before colocalization experiment, we had tested the toxicity of PDP-Cy5 by cell viability assay (Fig. S11). The $\mathrm{IC}_{50}$ was $3.45 \pm 0.71 \mu \mathrm{M}$, which was a tolerable value to living cells, meaning PDP-Cy5 could be used to visualize G-quadruplexes in live cells. To make it clearer, prefolded 100 pmol FAM labelled c-kit (DNA G-quadruplex) or BCL2 (RNA G-quadruplex) was transfected into HeLa cells by using lipofectamine 3000 for $4 \mathrm{~h}$, then incubated with $1 \mu \mathrm{M}$ PDP-Cy5 for 2h, and nuclei was dyed by 4', 6-diamidino-2-phenylindole (DAPI). 
After transfection, FAM labelled c-kit and BCL2 entered into live HeLa cells and located in cytoplasm as green fluorescence signal (the second column of images). Notably, incubation with PDP-Cy5 later, red fluorescence signal appeared at cytoplasm as well (the third column of images). Importantly, most red fluorescence signal colocated with green fluorescence signal (c-kit or BCL2 itself), which were observed as yellow regions in merged images (the fourth column of images). It revealed that PDP-Cy5 had been selectively bound to G-quadruplexes which we transfected into HeLa cells. Thus colocalization experiments in HeLa cells realized visualization of DNA and RNA G-quadruplexes on cell level.

[insert Fig. 4]

\section{Conclusions}

In summary, we have successfully synthesized a near-infrared fluorescent probe, named PDP-Cy5, combining the G-quadruplex ligand pyridostatin derivative (PDP) and Cy5 fluorophore in one compound, which realizes visualization of DNA and RNA G-quadruplexes through in vitro native gel electrophoresis, even on cell level. Compared with the previous works, this PDP-Cy5 probe successfully make a combination of the advantages of PDP and Cy5. Therefore, PDP-Cy5 selectively induced the formation of intramolecular G-quadruplexes with strong binding affinity and effectively stabilize G-quadruplexes. According to the investigation, PDP-Cy5 was highly selective for G-quadruplexes both in DNA and RNA, while eliminating interference of other structures of nucleic acids to the visualization of G-quadruplexes. 
Thanks to the G-quadruplex ligand pyridostatin derivative, PDP-Cy5 also performed the surprising capability of stabilizing G-quadruplexes, which improved $\mathrm{T}_{\mathrm{m}}$ by more than $20^{\circ} \mathrm{C}$, especially for RNA G-quadruplexes. After incubation with PDP-Cy5, RNA G-quadruplexes preserved its structure even at $90{ }^{\circ} \mathrm{C}$. And due to the advantages of Cy5 fluorophore, this compound can show the potential for near-infrared imaging. Considering the remarkable properties of PDP-Cy5, one can easily appreciate its promising application prospects in vitro and in vivo. For example, PDP-Cy5 may have an application in microarrays to screen G-quadruplex forming oligonucleotides.

\section{Acknowledgements}

This work was supported by the National Basic Research Program of China (973 Program) (2012CB720600, 2012CB720603), the National Science Foundation of China(21432008, 91413109, 21372182).

\section{References}

[1] S. Burge, G. N. Parkinson, P. Hazel, A. K. Todd, S. Neidle, Quadruplex DNA: sequence, topology and structure, Nucleic Acids Res. 2006, 34, 5402-5415.

[2] W. E. Wright, V. M. Tesmer, K. E. Huffman, S. D. Levene, J. W. Shay, Normal human chromosomes have long G-rich telomeric overhangs at one end, Genes Dev. 1997, 11, 2801-2809.

[3] J. L. Huppert, S. Balasubramanian, G-quadruplexes in promoters throughout the human genome, Nucleic Acids Res. 2007, 35, 406-413.

[4] H. Martadinata, A. T. Phan, Structure of propeller-type parallel-stranded RNA 
G-quadruplexes, formed by human telomeric RNA sequences in $\mathrm{K}^{+}$solution, J. Am. Chem. Soc. 2009, 131, 2570-2578.

[5] A. Bugaut, S. Balasubramanian, 5'-UTR RNA G-quadruplexes: translation regulation and targeting, Nucleic Acids Res. 2012, 40, 4727-4741.

[6] A. Arora, B. Suess, An RNA G-quadruplex in the 3' UTR of the proto-oncogene PIM1 represses translation, RNA Biol. 2011, 8, 802-805.

[7] J. D. Beaudoin, J. P. Perreault, Exploring mRNA 3'-UTR G-quadruplexes: evidence of roles in both alternative polyadenylation and mRNA shortening, Nucleic Acids Res. 2013, 41, 5898-5911.

[8] P. Ivanov, E. O'Day, M. Emara, G.Wagner, J. Lieberman, P. Anderson, G-quadruplex structures contribute to the neuroprotective effects of angiogenin-induced tRNA fragments, Proc. Natl. Acad. Sci. U. S. A. 2014, 111, 18201-18206.

[9] a) G. N. Parkinson, M. P. Lee, S. Neidle, Crystal structure of parallel quadruplexes from human telomeric DNA, Nature 2002, 417, 876-880. b) Y. Xu, Y. Noguchi, H. Sugiyama, G-quadruplex structure: a target for anticancer therapy and a probe for detection of potassium, Bioorg. Med. Chem. 2006, 14, 5584-5591.

[10] G. Biffi, D. Tannahill, J. McCafferty, S. Balasubramanian, Quantitative Visualization of DNA G-quadruplex Structures in Human Cells, Nat. Chem. 2013, 5, 182-186.

[11] G. Biffi, M. D. Antonio, D. Tannahill, S. Balasubramanian, Visualization and selective chemical targeting of RNA G-quadruplex structures in the cytoplasm of 
human cells, Nat. Chem. 2014, 6, 75-80.

[12] C. Schaeffer, B. Bardoni, J. L. Mandel, B. Ehresmann, C. Ehresmann, H. Moine, The fragile $\mathrm{X}$ mental retardation protein binds specifically to its mRNA via a purine quartet motif, EMBO J. 2001, 20, 4803-4813.

[13] A. Siddiqui-Jain, C. L. Grand, D. J. Bearss, L. H. Hurley, Direct evidence for a G-quadruplex in a promoter region and its targeting with a small molecule to repress c-MYC transcription, Proc. Natl. Acad. Sci. U. S. A. 2002, 99, 11593-11598.

[14] A. M. Zahler, J. R. Williamson, T. R. Cech, D. M. Prescott, Inhibition of telomerase by G-quartet DNA structures, Nature 1991, 350, 718-720.

[15] A. Rizzo, E. Salvati, M. Porru, C. D'Angelo, M. F. Stevens, M. D'Incalci, C. Leonetti, E. Gilson, G. Zupi, A. Biroccio, Stabilization of quadruplex DNA perturbs telomere replication leading to the activation of an ATR-dependent ATM signaling pathway, Nucleic Acids Res. 2009, 37, 5353-5364.

[16] W. Shen, L. Gao, M. Balakrishnan, R. A. A. Bambara, A recombination hot spot in HIV-1 contains guanosine runs that can form a G-quartet structure and promote strand transfer in vitro, J. Biol. Chem. 2009, 284, 33883 - 33893.

[17] Y. Hai, W. Cao, G. Liu, S.-P. Hong, S. A. Elela, R. Klinck, J. Chu, J. Xie, A G-tract element in apoptotic agents-induced alternative splicing, Nucleic Acids Res. $2008,36,3320-3331$.

[18] R. F. Macaya, P. Schultze, F. W. Smith, J. A. Roe, J. Feigon, Thrombin-binding DNA aptamer forms a unimolecular quadruplex structure in solution, Proc. Natl. Acad.

Sci. U. S. A. 1993, 90, 3745-3749. 
[19] J. L. Mergny, L. Lacroix, M. P. Teulade-Fichou, C. Hounsou, L. Guittat, M. Hoarau, P. B. Arimondo, J. P. Vigneron, J. M. Lehn, J. F. Riou, T. Garestier, C. Helene, Telomerase inhibitors based on quadruplex ligands selected by a fluorescence assay, Proc. Natl. Acad. Sci. U. S. A. 2001, 98, 3062-3067.

[20] M. P. Teulade-Fichou, C. Carrasco, L. Guittat, C. Bailly, P. Alberti, J. L. Mergny, A. David, J. M. Lehn, W. D. Wilson, Selective recognition of G-qQuadruplex telomeric DNA by a bis(quinacridine) macrocycle, J. Am. Chem. Soc. 2003, 125, $4732-4740$.

[21] C. L. Grand, H. Han, R. M. Muñoz, S. Weitman, D. D. Von Hoff, L. H. Hurley, D. J. Bearss, The cationic porphyrin TMPyP4 down-regulates c-MYC and human telomerase reverse transcriptase expression and inhibits tumor growth in vivo, Mol. Cancer. Ther. 2002, 1, 565-573.

[22] a) R. Rodriguez, S. Müller, J. A. Yeoman, C. Trentesaux, J. F. Riou, S. Balasubramanian, A novel small molecule that alters shelterin integrity and triggers a DNA-damage response at telomeres, J. Am. Chem. Soc. 2008, 130, 15758-15759. b) S. Müller, S. Kumari, R. Rodriguez, S. Balasubramanian, Small-molecule-mediated G-quadruplex isolation from human cells, Nat. Chem. 2010, 2, 1095-1098.

[23] J. Mohanty, N. Barooah, V. Dhamodharan, S. Harikrishna, P. I. Pradeepkumar, A. C. Bhasikuttan, Thioflavin $\mathrm{T}$ as an efficient inducer and selective fluorescent sensor for the human telomeric G-quadruplex DNA, J. Am. Chem. Soc. 2013, 135, 367-376. [24] L. Xu, D. Zhang, J. Huang, M. G. Deng, M. Zhang, X. Zhou, High fluorescence selectivity and visual detection of G-quadruplex structures by a novel dinuclear 
ruthenium complex, Chem. Commun. 2010, 46, 743-745.

[25] J. W. Yan, S. B. Chen, H. Y. Liu, W. Y. Ye, T. M. Ou, J. H. Tan, D. Li, L. Q. Gua, Z. S. Huang, Development of a new colorimetric and red-emitting fluorescent dual probe for G-quadruplex nucleic acids, Chem. Commun. 2014, 50, 6927-6930.

[26] F. He, Y. L. Tang, S. Wang, Y. L. Li, D. B. Zhu, for homogeneous potassium detection, J. Am. Chem. Soc. 2005, 127, 12343-12346.

[27] M. Tera, K. Iida, K. Ikebukuro, H. Seimiya, K. Shin-Ya, K. Nagasawa, Visualization of G-quadruplexes by using a BODIPY-labeled macrocyclic heptaoxazole, Org. Biomol. Chem. 2010, 8, 2749-55.

[28] X. Yang, L. Shen, H. Bao, X. Fang, J. Xu, Y. Zhao, W. Yang, A tricarbocyanine near-infrared fluorescent probe for sulfide through a copper displacement mechanism, Sensors and Actuators B: Chemical 2015, 220, 1361-1367.

[29] M. V. Kvach, A. V. Ustinov, I. A. Stepanova, A. D. Malakhov, M. V. Skorobogatyi, V. V. Shmanai, V. A. Korshun, A Convenient Synthesis of Cyanine Dyes: Reagents for the Labeling of Biomolecules, Eur. J. Org. Chem. 2008, 12, $2107-2117$.

[30] M. E. Jung, W. J. Kim, Practical syntheses of dyes for difference gel electrophoresis, Bioorg. Med. Chem. 2006, 14, 92-97.

[31] D. Monchaud, C. Allain, M. P. Teulade-Fichou, Development of a fluorescent intercalator displacement assay (G4-FID) for establishing quadruplex-DNA affinity and selectivity of putative ligands, Bioorg. Med. Chem. Lett. 2006, 16, 4842-4845. [32] I. Lubitz, D. Zikich, A. Kotlyar, Specific high-affinity binding of thiazole orange 
to triplex and G-quadruplex DNA, Biochemistry 2010, 49, 3567-3574.

[33] A. K. Tong, S. Jockusch, Z. Li, H. R. Zhu, D. L. Akins, N. J. Turro, J. Ju, Triple fluorescence energy transfer in covalently trichromophore-labeled DNA, J. Am. Chem. Soc. 2001, 123, 12923-12924.

[34] A. A. Marti, X. Li, S. Jockusch, N. Stevens, Z. Li, B. Raveendra, S. Kalachikov, I. Morozova, J. J. Russo, D. L. Akins, J. Ju, N. J. Turro, Design and characterization of two-dye and three-dye binary fluorescent probes for mRNA detection, Tetrahedron 2007, 63, 3591-3600.

\section{Biographies}

Fan Wu is a graduate student at Department of Chemistry, Wuhan University. She is currently pursuing her doctor's degree under the supervision of Prof. Zhou. Her research is concerning on biological testing based on nucleic acid.

Chaoxing Liu is a graduate student at Department of Chemistry, Sichuan University. And now he is studying for his doctorate in Wuhan University. His research is concerning on design and synthesis of novel chemo sensors.

Yuqi Chen is a graduate student at Department of Chemistry, Wuhan University. Her research is concerning on biological testing.

Shixi Yang is pursuing her B.S. degree in chemistry in Wuhan University. At present she is an undergraduate student in the laboratory. Her research interests focus on biological testing. 
Jiahui Xu is a graduate student at Department of Chemistry, Wuhan University and now she is pursuing her PhD. degree in Rutgers University, USA.

Rong Huang is a lecturer in South Central University for Nationalities. She obtained her PhD. degree in 2015 in Wuhan University (Wuhan, China). Her research interests focus on design new drugs.

Xiang Wang is studying for her B.S. degree in chemistry in Wuhan University. Her research is concerning on synthesis of functional fluorescent molecules.

Manjia Li is studying for her B.S. degree in chemistry in Wuhan University. Her research is concerning on design and synthesis of novel chemo sensors.

Wenting Liu is pursuing her $\mathrm{PhD}$. degree in chemistry in Wuhan University. Her research is concerning on biological testing.

Wuxiang Mao is an assistant professor in Hubei University. He obtained his Ph. D. degree in 2015 in Wuhan University. His research interests focus on the chemical biology research for disease diagnosis and treatment.

Xiang Zhou is a professor in Wuhan University and Changjiang Professor of the Ministry of Education of China. He obtained his Ph. D. degree in 1995 in Chinese University of Hong Kong. His research interests focus on the chemical biology research for disease diagnosis and treatment

Scheme 1. Near-Infrared fluorescent visualization of G-quadruplexes and structure of PDP-Cy5.

Scheme 2. Synthesis route for PDP-Cy5.

Fig. 1. CD analysis. A, B) Spectra of $8 \mu \mathrm{M}$ DNA G-quadruplex, c-kit (A) and RNA G-quadruplex, 
BCL2 (B) in 10 mM Tris-HCl, pH 7.4 in different conditions; black line: no salt added; red line: in presence of $100 \mathrm{mM} \mathrm{K}$; blue line: with 5.0 equiv. PDP-Cy5; green line: both with 5.0 equiv. PDP-Cy5 and $100 \mathrm{mM} \mathrm{K}$. C, D) melting curves of c-kit $(8 \mu \mathrm{M})$ with $5 \mathrm{mM} \mathrm{K}^{+}(\mathrm{C})$ and BCL2 with $500 \mu \mathrm{M} \mathrm{K}^{+}$(D) in $10 \mathrm{mM}$ Tris-HCl, $\mathrm{pH} 7.4$ in presence or absence of 5.0 equiv. PDP-Cy5, as monitored by the CD intensity at $265 \mathrm{~nm}$.

Tabel 1. $\Delta \mathrm{T}_{\mathrm{m}}$ of DNA and RNA G-quadruplex with 5.0 equiv. PDP-Cy5 obtained by CD melting curves.

Fig. 2. TO displacement curves obtained with DNAs (A) and RNAs (B). $0.25 \mu \mathrm{M}$ DNAs or RNAs prefolded in $10 \mathrm{mM}$ Tris- $\mathrm{HCl}, \mathrm{pH} 7.4$ with $100 \mathrm{mM} \mathrm{K}^{+}$, then added $0.5 \mu \mathrm{M}$ TO. All the data obtained by the fluorescence intensity at $530 \mathrm{~nm}$.

Tabel 2. $\mathrm{DC}_{50}$ of different RNA and DNA sequences in TO dis-placement assay.

Fig. 3. Visualization of G-quadruplexes by PDP-Cy5. A, B) G-quadruplexes (A: c-kit B: BCL2) induced in presence of different concentration of PDP-Cy5 in $10 \mathrm{mM}$ Tris-HCl, pH 7.4. Lane 1-6, $1 \mu \mathrm{M}$ oligonucleotides treated with $0,1,2,3,4,5 \mu \mathrm{M}$ PDP-Cy5 and no salt added. Lane 7 , oligonucleotides treated with $5 \mu \mathrm{M}$ PDP-Cy5 and $100 \mathrm{mM} \mathrm{K}$. C, D, E, F) DNA/RNA G-quadruplex and other structures in absence (Lane 1) or presence (Lane 2) of $5 \mu \mathrm{M}$ PDP-Cy5 with $100 \mathrm{mM} \mathrm{K}^{+}$in $10 \mathrm{mM}$ Tris-HCl, $\mathrm{pH}$ 7.4; Lane 3, $5 \mu \mathrm{M}$ PDP-Cy5 with $100 \mathrm{mM} \mathrm{K}{ }^{+}$and no DNA or RNA. All images were merged photos obtained by 490-530 nm band-pass filter (green, DNA or RNA itself) and 640-700 nm band-pass filter (red, PDP-Cy5) respectively.

Fig. 4. Colocalization images of HeLa cells transfected by 100 pmol c-kit or BCL2 using lipofectamine 3000 for $4 \mathrm{~h}$ then incubated with $1 \mu \mathrm{M}$ PDP-Cy5 for $2 \mathrm{~h}$. The blue signal is from the cell nuclei dyed with DAPI, the green fluorescence is from FAM labelled sequences, and the red 
fluorescence is from PDP-Cy5. All images shared same scale bar $(20 \mu \mathrm{m})$.

Scheme 1.

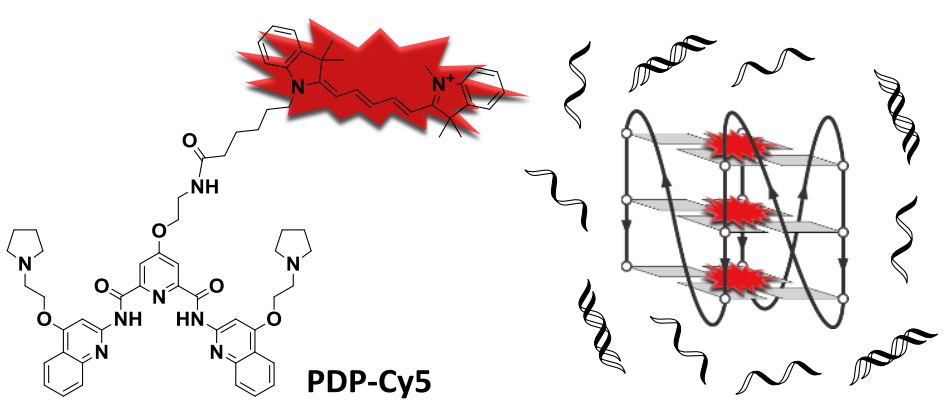

Scheme 2.

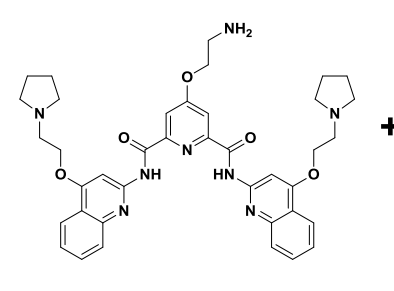

PDP

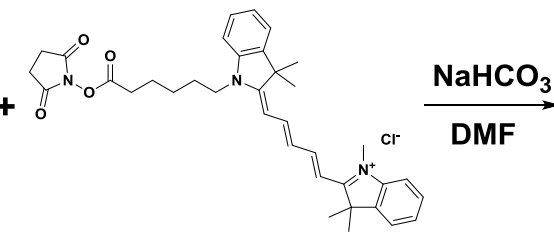

Cy5-NHS ester

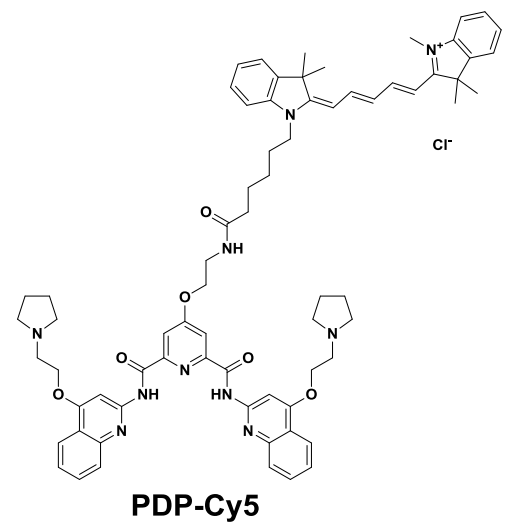

Fig. 1. 

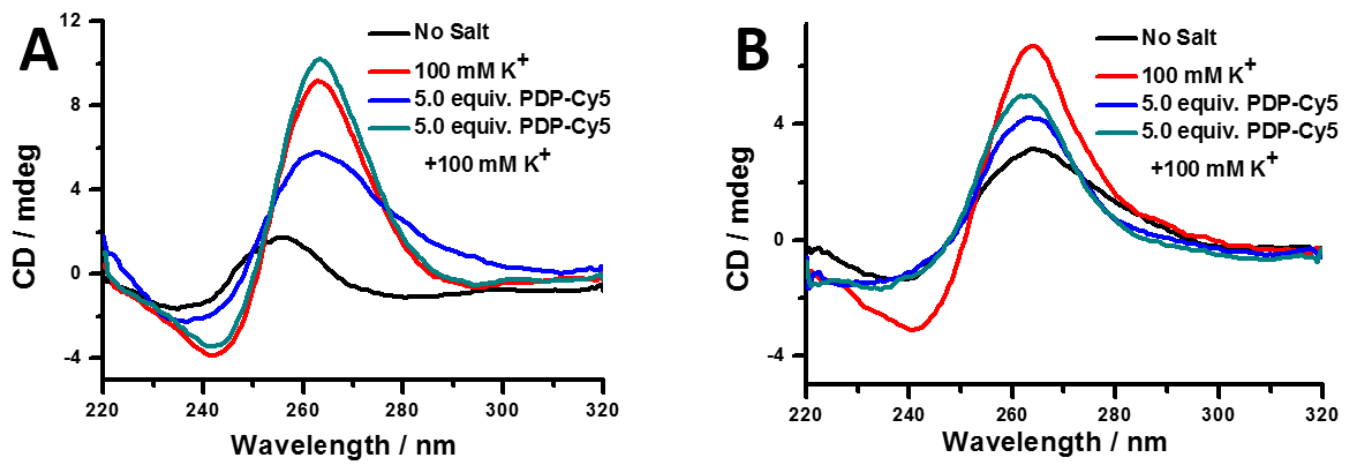

C

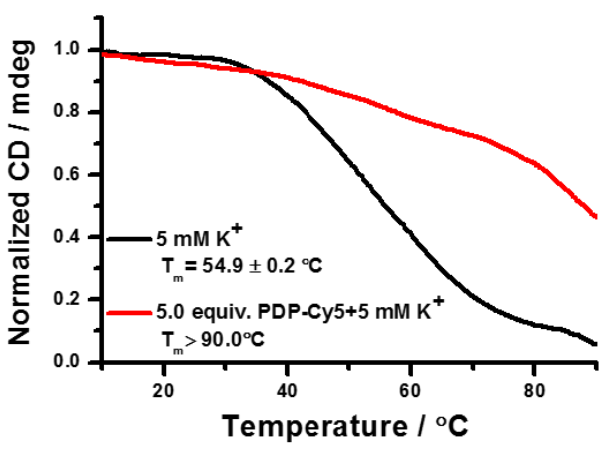

D

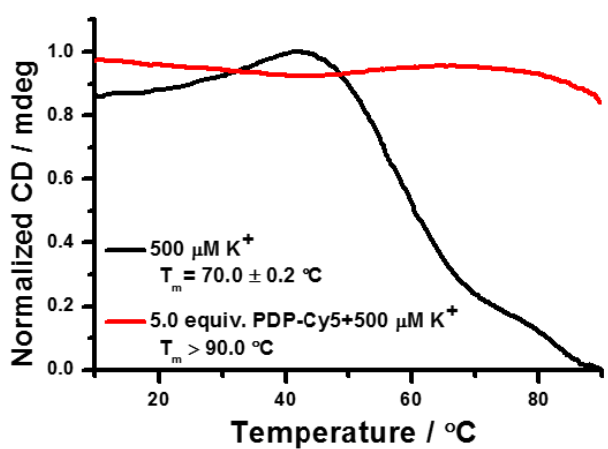

Tabel 1.

\begin{tabular}{llllllll}
\hline RNA/DNA & BCL2 & NRAS & TERRA & c-kit & c-myc & bcl27 & telo24 \\
\hline$\Delta \mathrm{T}_{\mathrm{m}} /{ }^{\circ} \mathrm{C}$ & $>20$ & $>30$ & $>50$ & $>40$ & 16.8 & 24.6 & 41.5 \\
\hline
\end{tabular}

Fig. 2.
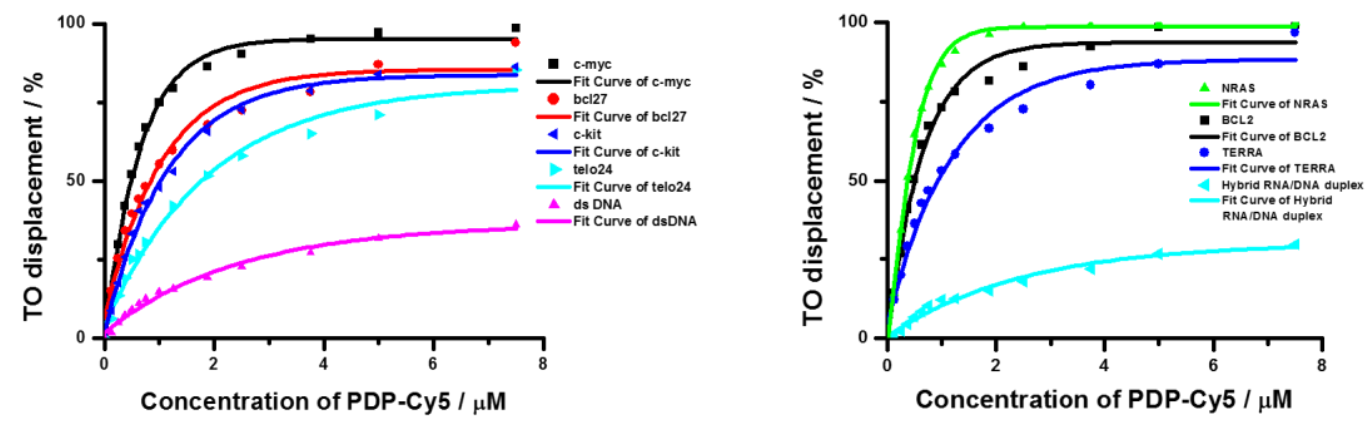

Tabel 2.

RNA/DNA BCL2 NRAS TERRA c-kit c-myc bcl27 telo24 dsDNA RNA/DNA 


\begin{tabular}{llllllllll}
\hline $\mathrm{DC}_{50} / \mu \mathrm{M}$ & 0.49 & 0.36 & 0.88 & 1.10 & 0.46 & 0.80 & 1.76 & $>7.5$ & $>7.5$ \\
\hline
\end{tabular}

Fig. 3.

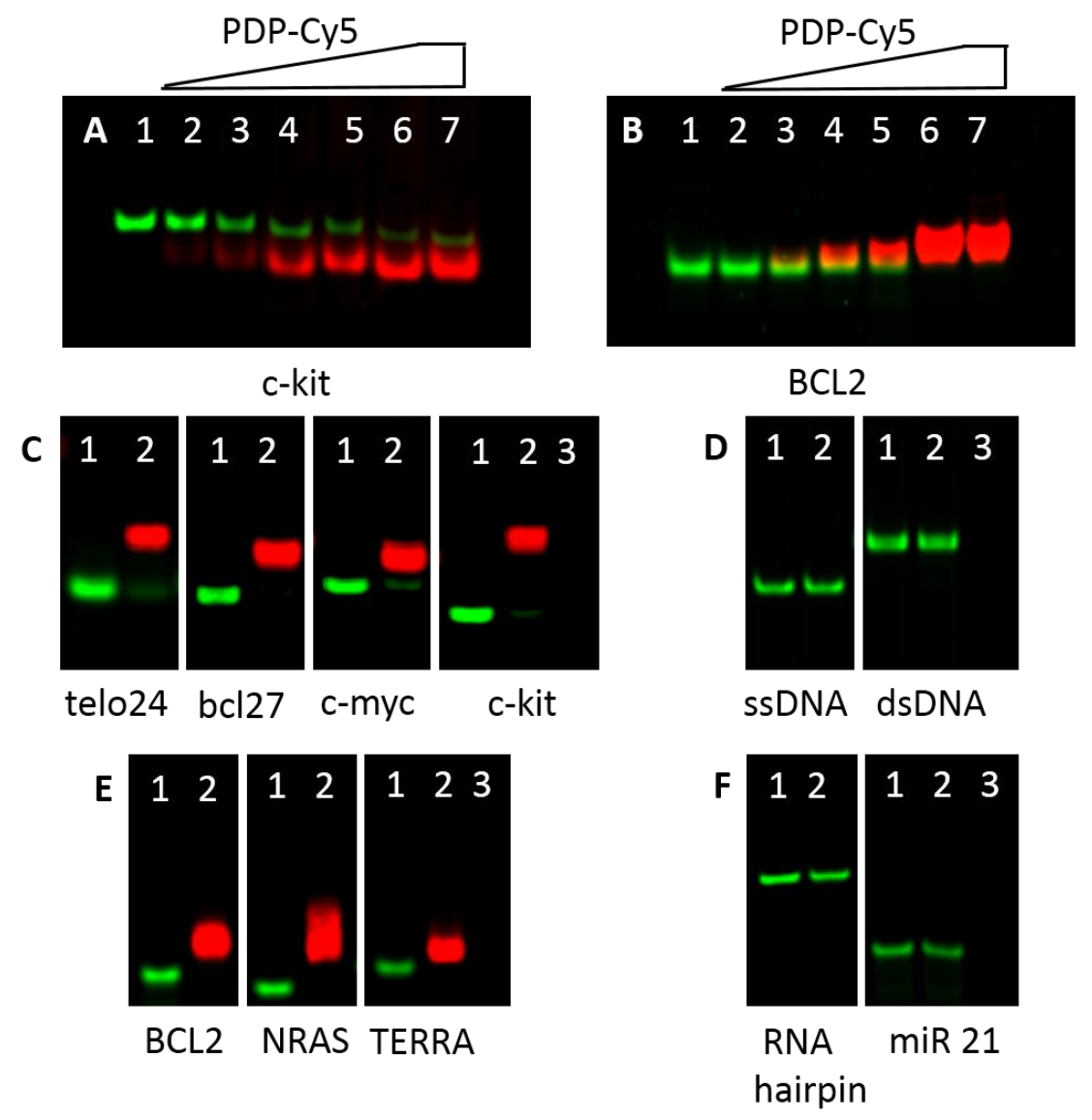

Fig. 4.

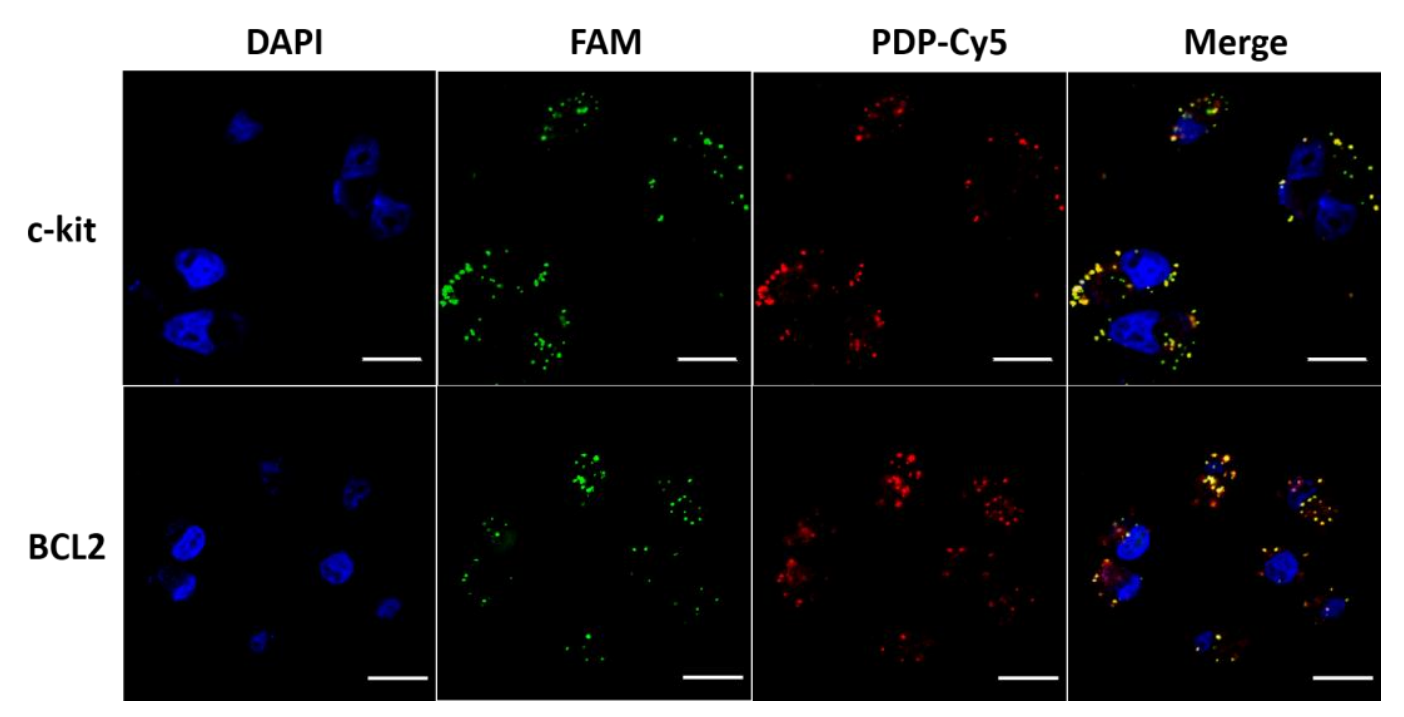

